Rev. Bras. Saúde Prod. Anim., Salvador, v.13, n.3, p.791-803 jul./set., 2012 http://www.rbspa.ufba.br

ISSN 15199940

\title{
Feno da rama de mandioca para suínos em terminação ${ }^{1}$
}

\author{
Cassava foliage hay for swine in finishing phase
}

\section{FIGUEIREDO, Agustinho Valente de ${ }^{2 *}$; ALBUQUERQUE, Daniel Medeiros de Noronha $^{3}$; LOPES, João Batista ${ }^{2}$; FARIAS, Leonardo Atta ${ }^{4}$; MARQUES, Caroline Moura $^{2}$; CARVALHO FILHO, Domingos Urquiza ${ }^{3}$}

\author{
${ }^{1}$ Pesquisa financiada pelo CNPq. \\ ${ }^{2}$ Universidade Federal do Piauí, Centro de Ciências Agrárias, Departamento de Zootecnia, Teresina, \\ Piauí, Brasil \\ ${ }^{3}$ Universidade Federal do Piauí, Centro de Ciências Agrárias, Programa de Pós-Graduação em Ciência \\ Animal, Teresina, Piauí, Brasil.. \\ ${ }^{4}$ Universidade Federal do Piauí, Centro de Ciências Agrárias, Departamento de Zootecnia, Bom Jesus, \\ Piauí, Brasil. \\ *Endereço para correspondência: agustinhov@yahoo.com.br
}

\section{RESUMO}

A pesquisa foi desenvolvida para avaliar a digestibilidade e metabolizabilidade aparente da matéria seca, da proteína bruta, da energia bruta e a disponibilidade de cálcio e de fósforo do feno da rama de mandioca em suínos na fase de terminação. Também avaliaram-se o desempenho, as características da carcaça e a viabilidade econômica das dietas compostas de diferentes níveis de inclusão do feno da rama de mandioca. No ensaio de metabolismo, quatro leitões foram alimentados com uma ração-referência e outros quatro receberam a ração-teste, com $30 \%$ de substituição da ração-referência pelo feno da rama de mandioca. No ensaio de desempenho, utilizaram-se quarenta animais, vinte machos e vinte fêmeas, dispostos em blocos ao acaso, com cinco tratamentos, quatro repetições. Os tratamentos consistiram dos níveis de $0 ; 5 ; 10 ; 15$ e $20 \%$ de inclusão do feno da rama de mandioca. Os valores digestíveis e metabolizáveis da matéria seca, da proteína bruta e da energia do feno da rama de mandioca para suínos na fase de terminação são: 33,24 e 29,86\%; 3,98 e 2,97\%; $1.386,2$ e $1.196,6 \mathrm{kcal} / \mathrm{kg}$, respectivamente, e a disponibilidade de cálcio e do fósforo, de 0,30 e $0,21 \%$. Observou-se que o consumo de ração, ganho de peso, conversão alimentar, rendimento de carcaça e o peso dos principais cortes de suínos não foram influenciados pela inclusão do feno da rama de mandioca nas dietas de suíno na fase de terminação até o nível de $20 \%$. Constatou-se que, no entanto, a inclusão de $10 \%$ de feno da rama de mandioca em dietas de suínos em terminação melhorou o rendimento financeiro da produção.

Palavras-chave: alimentos alternativos, avaliação de carcaça, avaliação econômica, Manihot esculenta, Crantz suinocultura

\section{SUMMARY}

This research was developed to evaluate the digestibility and metabolizability of dry matter, crude protein and gross energy and availability of calcium and phosphorus of the cassava foliage hay for finishing pig, as well as to evaluate the performance, carcass characteristic and economic viability of the experimental diets for these animals fed with different levels of inclusion of this by-product in the diets. In the metabolism assay, four pigs were fed with a standard ration and others four received a test ration, with $30 \%$ of substitution of the standard ration for the cassava foliage hay. In the performance assay, forty animals were distributed in a randomized block design, with five treatments and four replications. The treatments consisted of the experimental diets with the levels of $0 ; 5 ; 10 ; 15$ and $20 \%$ of inclusion of the cassava foliage hay. The values of the digestibility and metabolizability of the dry matter, crude protein, gross energy of the cassava foliage hay for growing pigs area are: 
33.24 e $29.86 \% ; 3.98$ e $2.97 \% ; 1,386.2$ e $1,196.6 \mathrm{kcal} / \mathrm{kg}$, respectively. The values of calcium and phosphorus availability they are 0.30 e $0.21 \%$, respectively. The feed intake, weight gain, feed conversion, carcass yield and weight of main cuts of pigs they are not influenced by inclusion of the cassava foliage hay in diets to the level of $20 \%$. However the inclusion of the level of $10 \%$ of the cassava foliage hay in diets of pig improve financial yield of production.

Keywords: alternative feed, carcass evaluation, economic assessment, Manihot esculenta Crantz, Swine culture

\section{INTRODUÇÃO}

A suinocultura brasileira é uma das mais competitivas do mundo e isso se deve, em grande parte, aos avanços alcançados nas áreas de genética, manejo, sanidade, ambiência e nutrição. Dentro da cadeia de produção de suínos, a alimentação representa o fator que mais onera a atividade, dessa forma, tona-se necessária a busca de alternativas alimentares que possam contribuir na redução dos custos, o qual sofre grande influência das altas de preço das commodities às épocas de entressafra ou flutuação cambial.

A mandioca (Manihot esculenta, Crantz) representa uma cultura de grande distribuição mundial. Sua produção está concentrada nos países em desenvolvimento, em que as raízes desempenham papel fundamental como fonte de energia para alimentação humana e animal. A parte aérea da mandioca (rama) não possui destinação adequada, porém apresenta teor de proteína bruta, em média de $14,73 \%$, o qual pode atingir valores próximos a $19 \%$, a depender da espécie e da fração da parte aérea analisada, e é considerado o terço superior mais rico neste nutriente (SOUZA et al., 2011).
Existem muitas pesquisas que divulgam a utilização da rama de mandioca como fonte de proteína para ruminantes (SATH et al., 2008; HUE et al., 2010) e até para humanos (MODESTI et al., 2007; TEO et al., 2010), enquanto que para monogástricos são poucas as informações na literatura.

Assim, objetivou-se, neste trabalho, avaliar a digestibilidade e a metabolizabilidade aparente da matéria seca, da proteína bruta, da energia bruta, bem como a disponibilidade de cálcio e de fósforo do feno da rama de mandioca em suínos na fase de terminação. Também avaliaram-se o desempenho, as características da carcaça, os parâmetros e a viabilidade econômica das dietas compostas de diferentes níveis de inclusão do feno da rama de mandioca.

\section{MATERIAL E MÉTODOS}

A pesquisa foi realizada no Galpão Experimental de Metabolismo e no Setor de Suinocultura do Departamento de Zootecnia do Centro de Ciência Agrárias da Universidade Federal do Piauí (DZO/CCA/UFPI) e as análises laboratoriais, no Laboratório de Nutrição Animal do DZO/CCA/UFPI, segundo as recomendações de (AOAC, 1990).

No ensaio de metabolismo dos nutrientes, foram utilizados oito leitões híbridos comerciais, machos castrados, com peso médio inicial de $59,1 \pm 3,9 \mathrm{~kg}$, os quais foram alojados, individualmente, em gaiolas de metabolismo, num delineamento experimental, em blocos casualizados, com base no peso inicial dos animais. Quatro animais receberam ração-controle à base de milho e farelo de soja, suplementada com minerais e vitaminas (Tabela 1), de forma a atender 
às exigências dos animais segundo Rostagno et al. (2005). Os outros quatro animais receberam ração teste com $30 \%$ de substituição da ração referência pelo feno da rama de mandioca.

$\mathrm{O}$ feno da rama de mandioca foi obtido pelo corte do terço superior da parte aérea da planta, no final do ciclo da cultura, em seguida, foi submetido ao processo de secagem ao sol por, aproximadamente, três dias, com posterior trituração do material para ser incorporado às dietas experimentais. Realizou-se coleta de uma amostra representativa do material para análise laboratorial. A composição das dietas experimentais do feno da rama de mandioca encontra-se na Tabela 1 (experimento metabolismo).

Tabela 1. Composição centesimal das dietas referência do feno da rama de mandioca

\begin{tabular}{lcc}
\hline Ingredientes & Ração Controle & Feno da rama de mandioca \\
\hline Milho & 75,70 & - \\
Farelo de soja, 48\% & 20,00 & - \\
Feno da rama de mandioca & - & - \\
Fosfato bicálcico & 1,45 & - \\
Sal & 0,35 & - \\
Óleo de soja & 1,00 & - \\
Suplemento mineral e vitamínico ${ }^{1}$ & 0,50 & - \\
Calcário calcítico & 0,70 & - \\
L - Lisina HCl & 0,28 & - \\
DL - Metionina & 0,02 & - \\
Total & 100,00 & 90,87 \\
& Composição calculada & 17,92 \\
\hline Matéria seca (\%) & 89,01 & 2,61 \\
Proteína bruta (\%) & 16,49 & 25,97 \\
Nitrogênio (\%) & 2,22 & - \\
Fibra bruta (\%) & 3,22 & - \\
Lisina digestível (\%) & 0,85 & 5,53 \\
Metionina digestível(\%) & 0,25 & $2,32^{2}$ \\
Matéria mineral (\%) & 3,77 & $0,75^{2}$ \\
Cálcio (\%) & 0,66 & $4.888^{3}$ \\
Fósforo disponível (\%) & 0,32 & \\
Energia metabolizável (kcal/kg) & 3.230 & -
\end{tabular}

${ }^{1}$ Conteúdo/Kg do produto: Vit. A - 630.000 I; Vit. D3 - 135.000; Vit. E - 2.475mg; Vit. k3 - 180mg; Vit. B1 - 101mg; Vit. B2 - 495mg; Vit. B6 - 101mg; Vit. B12 - 2.025mcg; Niacina - 3.150mg; Ácido Fólico - 56mg; Ácido Pantotênico - 1.575mg; Selênio - 67,50mg; Promotor de crescimento - 2.500mg.

${ }^{2}$ Com base na matéria seca.

${ }^{3}$ Energia bruta $(\mathrm{kcal} / \mathrm{kg})$.

No ensaio de metabolismo, a ração foi fornecida em duas refeições diárias, às 7:00 horas e às 16:00 horas, cuja quantidade foi calculada de acordo com o consumo no período de adaptação, com base no peso metabólico $\left(\mathrm{PV}^{0,75}\right)$ de cada unidade experimental. 
O período experimental teve duração de 15 dias, dos quais seis foram destinados à adaptação dos animais às gaiolas e às dietas experimentais, três para regularização dos alimentos no trato digestivo e seis para o período de coleta. Foi utilizado o método de coleta total de fezes e urina sem uso de marcador, conforme preconizado por Bayley (1971). As fezes coletadas, diariamente, foram pesadas e homogeneizadas, das quais, ainda, foi retirada uma alíquota de $20 \%$ do conteúdo total, que foi acondicionada em sacos plásticos e posteriormente, armazenada em freezer. No final do período experimental, as fezes foram descongeladas, homogeneizadas, e retirada uma amostra para análises de matéria seca, proteína bruta, fibra bruta, energia bruta, matéria mineral, cálcio e fósforo.

Recolheu-se a urina excretada em baldes plásticos, com tela na borda e que continha $20 \mathrm{~mL}$ de ácido clorídrico (1:1). Em seguida, procedeu-se a mensuração da urina, em proveta, e retirada de uma amostra de $10 \%$, a qual foi acondicionada em recipiente de plástico e armazenada também em freezer. Ao final do período experimental, a urina foi descongelada, homogeneizada, e uma nova amostra foi retirada. As mesmas análises realizadas nas amostras das fezes foram feitas nas amostras de urina e das rações experimentais. Deve-se ressaltar que para o cálculo da digestibilidade dos nutrientes utilizaram-se as fórmulas de Matterson et al. (1965). No ensaio de desempenho, estudaram-se as variáveis, ganho de peso, consumo de ração, conversão alimentar, características da carcaça e a viabilidade econômica das rações experimentais.

Foram utilizados quarenta leitões híbridos comerciais, dos quais vinte eram machos castrados e vinte fêmeas, com peso médio inicial de $60 \pm 4,6 \mathrm{~kg}$. O delineamento experimental foi $\mathrm{o}$ de blocos ao acaso, com base no peso inicial dos animais, com cinco tratamentos, quatro repetições, cuja unidade experimental foi representada por um macho e uma fêmea, alojados em baias com comedouros de concreto e bebedouros tipo "chupeta".

Os tratamentos consistiram da inclusão do feno da rama de mandioca (FRM) nas rações experimentais em níveis de $0 ; 5 ; 10 ; 15$ e $20 \%$ (Tabela 2 ). As rações foram formuladas para atender às exigências nutricionais dos animais, média de machos castrados e fêmeas de alto potencial genético com desempenho superior (ROSTAGNO et al., 2005). A composição centesimal das rações experimentais para $o$ ensaio de desempenho encontra-se apresentada na Tabela 2.

No galpão experimental, foram instalados um termômetro de máxima e de mínima e um higrômetro para o registro diário da temperatura e umidade relativa do ar.

Avaliaram-se os animais quanto ao ganho de peso e consumo de ração a cada quatorze dias. Quando a média dos animais da baia atingiu peso entre $90 \mathrm{e}$ $100 \mathrm{~kg}$ foram abatidos, após prévio jejum alimentar e dieta hídrica, para avaliação da carcaça, de acordo com o Método Brasileiro de Classificação de Carcaça - MBCC (ABCS, 1973).

O estudo da viabilidade econômica das rações testadas foi realizado segundo Farias et al. (2008), sem deixar de considerar a relação do custo médio da alimentação $(\mathrm{R} \$)$ sobre o ganho de peso médio (kg).

Os resultados de desempenho e das características de carcaça dos animais foram submetidos à análise de variância e de regressão e, ainda, relacionados com os níveis de inclusão do FRM nas dietas experimentais (SAS INSTITUTE, 1986). 
Rev. Bras. Saúde Prod. Anim., Salvador, v.13, n.3, p.791-803 jul./set., 2012 http://www.rbspa.ufba.br ISSN 15199940

Tabela 2. Composição centesimal das dietas experimentais de acordo com os níveis de inclusão do feno da rama de mandioca

\begin{tabular}{lrrrrr}
\hline \multirow{2}{*}{ Ingrediente (\%) } & \multicolumn{5}{c}{ Feno da rama de mandioca (\%) } \\
\cline { 2 - 6 } & \multicolumn{1}{c}{5} & \multicolumn{1}{c}{10} & \multicolumn{1}{c}{15} & \multicolumn{1}{c}{20} \\
\hline Milho & 74,95 & 69,08 & 62,99 & 56,60 & 50,10 \\
Soja extrusada, 37\% & 2,80 & 14,10 & 24,60 & 23,70 & 23,00 \\
Farelo de soja, 48\% & 19,70 & 9,40 & 0,00 & 0,00 & 0,00 \\
Fosfato bicálcico & 0,80 & 0,75 & 0,75 & 0,75 & 0,72 \\
Sal & 0,35 & 0,37 & 0,35 & 0,35 & 0,35 \\
Óleo de soja & 0,00 & 0,00 & 0,15 & 2,55 & 4,90 \\
Suplemento mineral e vitamínico ${ }^{1}$ & 0,40 & 0,40 & 0,40 & 0,40 & 0,40 \\
Feno da rama de mandioca & 0,00 & 5,00 & 10,00 & 15,00 & 20,00 \\
Calcário calcítico & 0,95 & 0,87 & 0,75 & 0,65 & 0,53 \\
L - Lisina HCl & 0,05 & 0,03 & 0,01 & 0,00 & 0,00 \\
Total & 100,00 & 100,00 & 100,00 & 100,00 & 100,00 \\
\hline \multicolumn{5}{c}{} \\
\hline Matéria seca (\%) & Composição analisada & & \\
Proteína bruta (\%) & 87,58 & 86,58 & 88,16 & 88,48 & 87,72 \\
Fibra bruta (\%) & 16,98 & 16,93 & 16,15 & 15,01 & 17,19 \\
Matéria Mineral (\%) & 5,42 & 5,76 & 6,28 & 7,51 & 8,21 \\
Energia bruta (kcal/kg) & 3,30 & 4,22 & 4,49 & 4,18 & 4,59 \\
I'Conteúdo/Kg do produto: Vit. A - 630.000Ui; Vit. D3 - 135.000; Vit. E - 2.475mg; Vit. k3 - 180mg; \\
Vit. B1 - 101mg; Vit. B2 - 495mg; Vit. B6 - 101mg; Vit. B12 - 2.025mcg; Niacina - 3.150mg; Ácido \\
Fólico - 56mg; Ácido Pantotênico - 1.575mg; Selênio - 67,50mg; Promotor de crescimento - 2.500mg.
\end{tabular}

\section{RESULTADOS E DISCUSSÃO}

Os coeficientes de digestibilidade e de metabolizabilidade da matéria seca, da proteína bruta e da energia bruta do feno da rama de mandioca (Tabela 3) foram de 36,54 e $32,86 \% ; 22,22$ e $16,57 \% ; 28,36$ e 24,48\%, respectivamente. Assim, os valores digestíveis e metabolizáveis da matéria seca e da proteína foram de 32,24 e $29,86 \%$ e 3,98 e $2,97 \%$, respectivamente. Esses resultados sugerem que os suínos em terminação, ainda que apresentassem um sistema enzimático mais desenvolvido que os leitões mais jovens, possuíam capacidade limitada de aproveitamento de nutrientes. Essa observação pode estar vinculada ao elevado teor de fibra bruta $(25,97 \%)$ presente no feno da rama de mandioca, que provoca, como consequência, o aumento dos movimentos peristálticos, de forma a diminuir o tempo de permanência da dieta no trato gastrintestinal e interferir na absorção de todos nutrientes (PARTANEN et al., 2007).

A fibra, na dieta, pode adsorver-se a proteína e aminoácidos, de modo a torná-los indisponíveis para digestão e absorção, o que justifica o baixo aproveitamento da proteína desse ingrediente no presente estudo $(22,22 \%)$. Segundo Partanen et al. (2007), a inclusão de fibra na dieta de suínos diminui linearmente a digestibilidade da proteína bruta. Outro problema causado pela fibra no trato gastrintestinal dos animais monogástricos diz respeito à descamação mecânica do trato digestório, o que 
aumenta a excreção de proteína endógena.

$\mathrm{O}$ aproveitamento da proteína pode ter sido influenciado negativamente pela presença de taninos na folha da mandioca que formam, com a proteína do alimento e com a proteína das enzimas digestivas, complexos insolúveis, de forma a reduzir a digestibilidade da proteína bruta. $\mathrm{O}$ teor de tanino das folhas da mandioca varia entre 0,6 a $1,2 \%$ da matéria seca e é maior em plantas mais maduras (TEO et al., 2010).

Tabela 3. Coeficientes de digestibilidade e metabolizabilidade e valor nutricional dos nutrientes do feno da rama de mandioca para suínos em terminação

\begin{tabular}{lcccc}
\hline Variável & \multicolumn{2}{c}{ Coeficiente $(\%)$} & \multicolumn{2}{c}{ Valor Nutricional } \\
\cline { 2 - 5 } & Digestibilidade & Metolizabilidade & Digestível & Metabolizável \\
\hline Matéria seca & 36,54 & 32,86 & 33,24 & 29,86 \\
Proteína & 22,22 & 16,57 & 3,98 & 2,97 \\
Energia & 28,36 & 24,48 & $1.386,2$ & $1.196,6$ \\
Fibra & 7,37 & - & 1,91 & - \\
Cálcio & 13,49 & 13,10 & - & $0,30^{1}$ \\
Fósforo & 27,45 & 27,35 & - & $0,21^{1}$ \\
\hline
\end{tabular}

${ }^{\mathrm{I}}$ Disponível.

Observou-se que, embora o valor da energia bruta do feno da rama de mandioca seja elevado $(4.888 \mathrm{kcal} / \mathrm{kg})$, a digestibilidade desse nutriente, para suínos em terminação, foi de $28,36 \%$ (Tabela 3), o que totaliza, dessa forma, quase dois terços da energia eliminados nas fezes. Isso ocorre, provavelmente, em função de grande parte dessa energia estar sob a forma de celulose, um polissacarídeo de alto valor energético, mas de pouco aproveitamento por monogástricos.

A digestibilidade aparente da fibra bruta na fase de terminação foi de $7,37 \%$, o que mostra que a fibra, praticamente, não foi desdobrada, nem na porção final do trato digestório dos animais testados. Já os valores da energia digestível e metabolizável do feno da rama de mandioca, para suínos em terminação, foram, respectivamente, de 1.386,2 e $1196,6 \mathrm{kcal} / \mathrm{kg}$. Com relação à energia digestível, o resultado obtido, neste experimento, foi inferior ao de outros ingredientes alternativos para suínos como milheto, $3.171 \mathrm{kcal} / \mathrm{kg}$ (BASTOS et al., 2006), resíduo de cervejaria, $2.628 \mathrm{kcal} / \mathrm{kg}$ (ALBUQUERQUE et al., 2011) e da casca de café variedade melosa, $2.494 \mathrm{kcal} / \mathrm{kg}$. Porém, muito próximo ao valor da energia digestível da casca de café, variedade seca, com $1.236 \mathrm{kcal} / \mathrm{kg}$ (PARRA et al., 2008) e do pseudofruto do cajueiro, com $1.123 \mathrm{kcal} / \mathrm{kg}$ (FARIAS et al., 2008).

Os índices percentuais de aproveitamento do cálcio e do fósforo do feno da rama de mandioca para suínos em terminação foram 13,49 e $27,45 \%$, respectivamente. Já os valores da disponibilidade desses nutrientes foram, respectivamente, de 0,30 e $0,21 \%$. Desse modo, praticamente todo o cálcio presente no feno da rama de mandioca é excretado, e somente, aproximadamente, um terço do fósforo se encontra disponível. Pela origem do alimento (vegetal), a baixa disponibilidade do fósforo era esperada, pois os monogástricos não produzem fitase, o que reduz a eficiência no aproveitamento do fósforo fítico 
(OLIVEIRA et al., 2009). No entanto, a disponibilidade do cálcio também pode ser afetada pela presença do fitato, que forma complexos insolúveis com o fósforo, em $\mathrm{pH}$ ácido, principalmente, no intestino delgado (SELLES et al., 2009).
O balanço de nitrogênio (Tabela 4) das dietas utilizadas foi positivo e compreendeu o menor valor encontrado na dieta teste. Isso aponta que o feno da rama de mandioca interfere no metabolismo da proteína, como era esperado por ser rico em fibra e taninos.

Tabela 4. Balanço de nitrogênio das dietas experimentais e energia digestível e metabolizável das dietas e do feno da rama de mandioca (FRM) para suínos em terminação

\begin{tabular}{lc}
\hline Variáveis & Valores \\
\hline Balanço de nitrogênio da dieta-controle (g/dia) & 34,30 \\
Balanço de nitrogênio da dieta-teste $-30 \%$ do FRM (g/dia) & 23,92 \\
Energia digestível do FRM $(\mathrm{kcal} / \mathrm{kg})$ & $1.386,2$ \\
Energia metabolizável do FRM $(\mathrm{kcal} / \mathrm{kg})$ & $1.196,6$ \\
\hline
\end{tabular}

Durante o ensaio de desempenho, a temperatura média e a umidade relativa média do ar, medida em termômetro de bulbo seco e úmido, registradas foram de $29 \pm 4,4^{\circ} \mathrm{C}$ e $62,20 \pm 12,0 \%$, respectivamente. Já o mínimo e máximo desses mesmos traços, foram de 25,9 e $32,2^{\circ} \mathrm{C}$ e 51 e $75 \%$, respectivamente.

De acordo com Leal \& Nããs (1992), a temperatura ideal para suínos em terminação se encontra entre 12 e $18^{\circ} \mathrm{C}$, e a temperatura crítica superior a $27^{\circ} \mathrm{C}$ e inferior a $4^{\circ} \mathrm{C}$. Durante o experimento, a temperatura média ficou acima da temperatura crítica superior para suínos em terminação. Nessas condições climáticas de altas temperaturas, os suínos normalmente diminuem a ingestão de alimentos.

No presente estudo, a temperatura não influenciou o consumo de alimento dos suínos, que em média (tratamentos) consumiram $2,750 \mathrm{~kg} / \mathrm{dia}$, valor próximo às médias observadas em ambiente termoneutro. White et al. (2008) observaram, em ambiente termoneutro $\left(23,9^{\circ} \mathrm{C}\right)$ e quente $\left(32,2^{\circ} \mathrm{C}\right)$, média de consumo de $3,05 \mathrm{~kg}$ e de $2,15 \mathrm{~kg}$, respectivamente. $\mathrm{O}$ consumo foi superior ao observado por Kiefer et al. (2010), que verificaram consumo médio de $2,54 \mathrm{~kg}$ em ambiente termoneutro $\left(21^{\circ} \mathrm{C}\right)$ e de $1,61 \mathrm{~kg}$ em ambiente quente $\left(32^{\circ} \mathrm{C}\right)$. Isso pode ser atribuído à adaptação dos animais, nascidos na região, que, por sua vez, alcança altas temperaturas ao longo do ano.

No tocante às variáveis relacionadas ao desempenho (Tabela 5), não houve influência $(\mathrm{P}>0,05)$ dos níveis de feno da rama de mandioca sobre o consumo de ração, ganho de peso e conversão alimentar. Apesar da fibra bruta da dieta, composta por $20 \%$ de inclusão do FRM, apresentar superioridade de $70 \%$ de fibra em relação à da ração controle, nenhuma das variáveis de desempenho foi influenciada. Tal ocorrência pode ser explicada pelo alto nível de óleo da dieta $(4,90 \%)$, usado para compensar queda nos níveis de energia. Os lipídios inibem o esvaziamento do trato digestivo, de forma a diminuir a frequência $e$ intensidade dos movimentos peristálticos, o que permite, ainda, maior tempo de contato das enzimas com o alimento no 
lúmen. Além disso, pode ser considerado palatabilizante para suínos e é capaz de aumentar a digestibilidade de alguns aminoácidos, devido a estímulo na secreção de suco pancreático (PUPA, 2004; ALMEIDA et al., 2007).

De acordo com a Tabela 5, observa-se que as variáveis de desempenho não foram afetadas $(\mathrm{P}>0,05)$ pelos níveis de inclusão do feno de rama de mandioca. Por outro lado, Ly et al. (2011), em trabalho com suínos na fase de crescimento, com níveis de inclusão de $0,10,15$ e $20 \%$ de rama de mandioca, observaram decréscimo no ganho de peso com a inclusão do alimento teste e decréscimo no peso final dos suínos. Os autores atribuíram a queda nas variáveis, provocada pela deficiência de aminoácidos essenciais nas folhas da mandioca, principalmente, metionina, ao maior nível de ácido cianídrico nas rações com 15 e $20 \%$ de inclusão.

Tabela 5. Desempenho de suínos em terminação alimentados com dietas contendo diferentes níveis de inclusão do feno da rama de mandioca (FRM)

\begin{tabular}{|c|c|c|c|c|c|c|}
\hline \multirow[t]{2}{*}{ Variáveis } & \multicolumn{6}{|c|}{ Níveis de inclusão do FRM (\%) } \\
\hline & 0 & 5 & 10 & 15 & 20 & $\mathrm{CV}(\%)$ \\
\hline Consumo de ração $(\mathrm{kg})^{1}$ & 2,910 & 2,680 & 2,722 & 2,832 & 2,605 & 10,92 \\
\hline Ganho de peso $(\mathrm{kg})^{1}$ & 0,825 & 0,765 & 0,760 & 0,820 & 0,872 & 9,45 \\
\hline Conversão alimentar ${ }^{1}$ & 3,540 & 3,515 & 3,627 & 3,467 & 2,997 & 9,39 \\
\hline
\end{tabular}

${ }^{\mathrm{I}}$ Não foi observado diferenças significativas entre os tratamentos $(\mathrm{P}>0,05)$.

Neste estudo, não foi aferido o teor de ácido cianídrico, nem de taninos, mas é possível que o processo de fenação da folha da mandioca tenha sido mais eficiente na remoção desses compostos, que o processo utilizado pelos autores supracitados, que procederam a secagem por apenas 24 horas e, em seguida, ensilaram o produto em sacos de nylon, além de, no experimento que se apresenta, terem-se utilizados animais em terminação com maior habilidade digestória que animais em crescimento. Nesse contexto, Corrêa et al. (2002) relatam que existem glicosídeos cianogênicos nas folhas frescas da mandioca ( linamarina e lotaustralina), que ao hidrolisarem, sob ação da enzima linamarase, liberam o ácido cianídrico, tóxico aos seres humanos e animais. Essa liberação pode ocorrer por danificação mecânica ou perda da integridade fisiológica, a qual se manifesta nos casos de murchamento das folhas.

Observou-se que o peso e os valores percentuais da carcaça, pernil, paleta, carré, barriga, bem como o comprimento de carcaça e a espessura do toucinho (Tabela 6) não foram influenciados $(\mathrm{P}>0,05)$ pelos níveis de feno da rama de mandioca. Porém, os cortes, dianteiro e costela, em termos de peso absoluto, apresentaram relação quadrática com os níveis de inclusão do feno, de acordo com a equação $\mathrm{y}=3,999+0,1845 \quad \mathrm{x} \quad-0,0083 \mathrm{x}^{2} \quad\left(\mathrm{R}^{2}=\right.$ 0,5796 ; $\mathrm{P}<0,01$; Figura 1) e $\mathrm{y}=3,9714+$ $0,0724 x-0,004 x^{2}\left(R^{2}=0,5302 ; P<0,05\right.$; Figura 2), respectivamente. Os níveis de inclusão para maior produção do corte dianteiro e costela foram 11,2 e $9,05 \%$, respectivamente para suínos em terminação. Os valores percentuais do rendimento desses cortes não foram influenciados pelos níveis do alimento testado. 
Tabela 6. Características de carcaças e principais cortes de suínos em terminação alimentados com diferentes níveis de inclusão do feno da rama de mandioca (FRM)

\begin{tabular}{|c|c|c|c|c|c|c|}
\hline \multirow{2}{*}{ Variáveis } & \multicolumn{5}{|c|}{ Níveis de inclusão do FRM (\%) } & \multirow{2}{*}{$\mathrm{CV}(\%)$} \\
\hline & 0 & 5 & 10 & 15 & 20 & \\
\hline Peso de abate (kg) & 93,08 & 96,80 & 95,65 & 92,53 & 91,60 & 4,75 \\
\hline Peso da carcaça quente (kg) & 66,75 & 70,10 & 67,78 & 66,75 & 62,18 & 7,00 \\
\hline Comprimento da carcaça $(\mathrm{cm})$ & 86,43 & 91,33 & 86,83 & 89,63 & 86,63 & 2,70 \\
\hline Espessura do toucinho $(\mathrm{cm})$ & 3,56 & 3,57 & 3,84 & 3,40 & 3,28 & 15,55 \\
\hline Pernil (kg) & 11,39 & 12,07 & 11,60 & 10,97 & 11,14 & 8,71 \\
\hline Paleta (kg) & 5,42 & 5,58 & 5,77 & 5,27 & 5,68 & 6,24 \\
\hline Carré (kg) & 4,61 & 4,09 & 3,64 & 3,86 & 3,13 & 21,50 \\
\hline Barriga (kg) & 3,33 & 3,66 & 4,43 & 3,93 & 3,77 & 21,64 \\
\hline Dianteiro $(\mathrm{kg})^{1}$ & 3,83 & 4,84 & 4,22 & 5,36 & 4,04 & 15,64 \\
\hline \multirow[t]{2}{*}{ Costela $(\mathrm{kg})^{2}$} & 3,86 & 4,52 & 4,11 & 4,13 & 3,88 & 11,48 \\
\hline & \multicolumn{5}{|c|}{ Valores percentuais } & \\
\hline Rendimento de carcaça (\%) & 71,21 & 71,08 & 67,63 & 73,99 & 70,82 & 4,98 \\
\hline Pernil (\%) & 34,28 & 34,40 & 34,24 & 32,84 & 34,86 & 6,98 \\
\hline Paleta $(\%)$ & 16,41 & 15,92 & 17,07 & 15,77 & 17,80 & 8,20 \\
\hline Carré $(\%)^{3}$ & 13,73 & 11,66 & 10,72 & 11,54 & 9,76 & 18,53 \\
\hline Barriga $(\%)$ & 10,24 & 10,50 & 13,09 & 11,72 & 11,87 & 24,32 \\
\hline Dianteiro $(\%)$ & 12,34 & 13,76 & 12,37 & 16,09 & 12,57 & 12,22 \\
\hline Costela $(\%)$ & 12,47 & 12,85 & 12,07 & 13,36 & 12,17 & 9,57 \\
\hline
\end{tabular}

${ }^{1}$ Efeito quadrático $(\mathrm{P}<0,05) ;{ }^{2}$ Efeito quadrático $(\mathrm{P}<0,01) ;{ }^{3}$ Efeito linear $(\mathrm{P}<0,05)$. 
Rev. Bras. Saúde Prod. Anim., Salvador, v.13, n.3, p.791-803 jul./set., 2012 http://www.rbspa.ufba.br ISSN 15199940

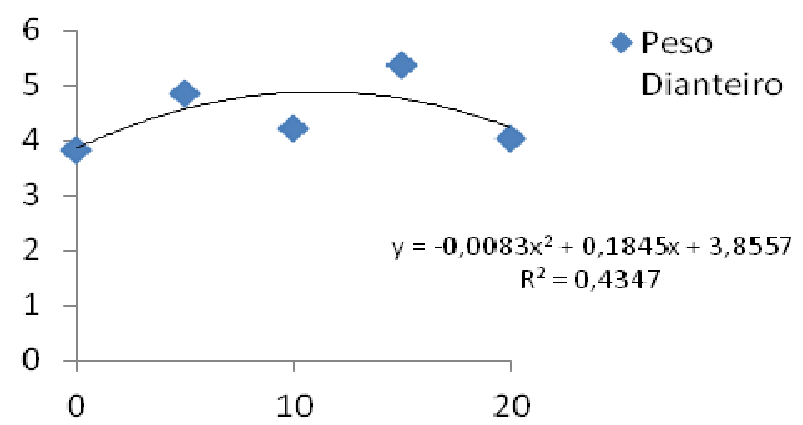

Figura 1. Valores do peso dianteiro em função dos níveis de inclusão de FRM

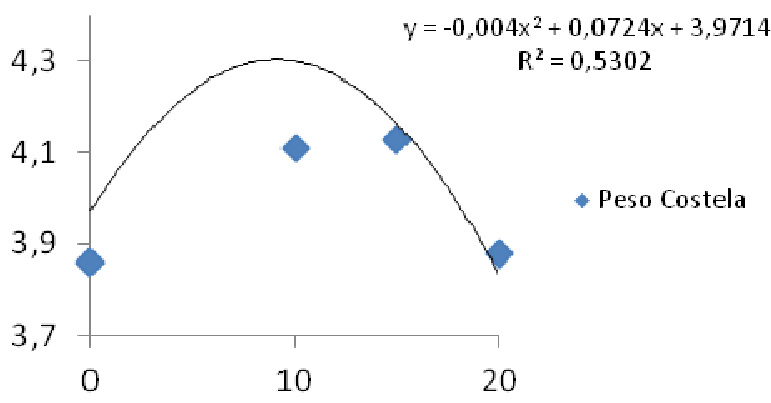

Figura 2. Valores do peso costela em função dos níveis de inclusão de FRM

Constatou-se que os valores percentuais do corte carré foram influenciados pelos níveis de inclusão do feno da rama de mandioca, de forma a apresentar uma relação linear $(\mathrm{P}<0,05)$, de acordo com a equação $\mathrm{y}=13,094-0,612804 \mathrm{x}$
$\left(\mathrm{R}^{2}=0,7524 ; \mathrm{P}<0,05\right.$ Figura 3$)$, o que evidencia uma piora do rendimento desse corte nobre, à medida que se aumentou a inclusão do feno da rama de mandioca.

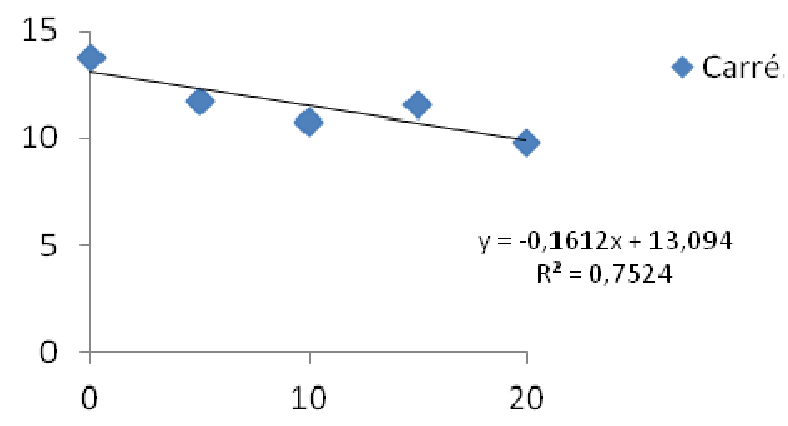

Figura 3. Valores do percental do carré em função dos níveis de inclusão de FRM 
Para a viabilidade econômica (Tabela 7), verificou-se que a menor relação do custo total da ração pelo ganho de peso médio foi de 3,63 , o que corresponde ao nível de $10 \%$ de inclusão do feno da rama de mandioca. Entretanto, essa relação para as rações com 5 e $15 \%$ de inclusão do feno apresentou-se superior à da ração padrão. A melhor renda bruta média foi obtida com $10 \%$ de inclusão do feno da rama de mandioca, nível que proporcionou o melhor retorno econômico ao produtor.

Tabela 7. Viabilidade econômica de rações com diferentes níveis de inclusão do feno da rama de mandioca (FRM) para suínos na fase de terminação

\begin{tabular}{|c|c|c|c|c|c|}
\hline \multirow{2}{*}{ Variáveis } & \multicolumn{5}{|c|}{ Níveis de inclusão do FRM, \% } \\
\hline & 0 & 5 & 10 & 15 & 20 \\
\hline Consumo de ração $(\mathrm{kg})$ & 212,34 & 192,05 & 195,24 & 204,14 & 186,55 \\
\hline Ganho de peso - GP $(\mathrm{kg})$ & 30,08 & 27,25 & 31,60 & 29,51 & 31,30 \\
\hline Custo médio da ração $(\mathrm{R} \$ / \mathrm{kg})^{1}$ & 0,58 & 0,58 & 0,59 & 0,61 & 0,64 \\
\hline Custo total da alimentação - CTA $(\mathrm{R} \$)^{2}$ & 122,90 & 111,79 & 114,81 & 125,17 & 119,17 \\
\hline Relação CTA:GP & 4,09 & 4,10 & 3,63 & 4,24 & 3,83 \\
\hline Renda bruta média & 254,91 & 250,32 & 257,29 & 253,37 & 251,48 \\
\hline
\end{tabular}

${ }^{\mathrm{T}}$ Valor médio dos ingredientes / kg; coletados em agosto de 2010.

${ }^{2}$ Custo médio da ração x consumo médio da ração $(\mathrm{R} \$)$.

Os resultados da viabilidade econômica das dietas formadas por diferentes níveis de inclusão do feno da rama de mandioca para suíno em terminação, associados ao satisfatório ganho de peso dos animais nesses níveis, indicam que o FRM pode representar uma alternativa alimentar para esses animais, principalmente, às épocas de entressafra, quando há alta no preço de milho e soja. Resultado semelhante foi observado por Ly et al. (2011), que forneceram rama de mandioca para suínos na fase de crescimento e obtiveram um retorno econômico melhor à medida que se incluía o alimento teste na dieta, sem piorar a conversão alimentar.

Os valores digestíveis e metabolizáveis da matéria seca, da proteína bruta e da energia do feno da rama de mandioca para suínos na fase de terminação, foram, a saber: 33,24 e $29,86 \%$; 3,98 e $2,97 \%$; $1.386,2 \mathrm{kcal} / \mathrm{kg}$ e $1.196,6 \mathrm{kcal} / \mathrm{kg}$, respectivamente, e a disponibilidade de cálcio de 0,30 e a do fósforo de $0,21 \%$.
Constatou-se que o consumo de ração, ganho de peso, conversão alimentar, o rendimento de carcaça e o peso dos principais cortes de suínos não são influenciados pela inclusão do feno da rama de mandioca nas dietas de suíno na fase de terminação até o nível de $20 \%$, no entanto, o rendimento em porcentagem do corte carré diminui linearmente com a inclusão do alimento teste. Contudo, a inclusão de $10 \%$ de feno da rama de mandioca em dietas de suínos em terminação apresenta melhor rendimento financeiro da produção.

\section{REFERÊNCIA}

ALBUQUERQUE, D.M.N.; LOPES, J.B.; KLEIN JÚNIOR, M.H.; MERVAL, R.R.; SILVA, F.E.S.; TEIXEIRA, M.P.F. Resíduo desidratado de cervejaria para suínos em terminação. Arquivo Brasileiro de Medicina Veterinária e Zootecnia, v.63, n.2, p.465-472, 2011. 
ALMEIDA, E.C.; FIALHO, E.T.;

CANTARELLI, V.S.; ZANGERONIMO, M.G.; PEREIRA R.A.N.; RODRIGURES, P.B.

Digestibilidade ileal e perdas endógenas de aminoácidos de dietas com óleo de soja para suínos em crescimento. Revista Brasileira de Zootecnia, v.36, n.4, p.1045-1051, 2007. Supl.

ASSOCIAÇÃO BRASILEIRA DE CRIADORES DE SUIINOS - ABCS.

Método brasileiro de classificação de carcaças. Estrela, RS, 1973. 17p. (Publicação Técnica, 2).

ASSOCIATION OF OFFICIAL ANALYTICAL CHEMISTS - AOAC . Official methods of analysis. 15. ed. Washington, DC: AOAC, 1990.

BASTOS A.O.; MOREIRA I.; FURLAN A.C.; OLIVEIRA, G.C.; FRAGA, A.L.; SARTORI, I.M. Efeitos da inclusão de níveis crescentes de milheto (Pennisetum Glaucum (L.) R. Brown) grão na alimentação de suínos em crescimento e terminação. Revista Brasileira de Zootecnia, v.35, n.1, p.98-103, 2006.

BAYLEY, H.A. A critical review of energy measurements for swine.

Feedstufs, v.43, n.11, p.34-36, 1971.

CORRÊA, A.D.; SANTOS, C.D.; NATIVIDADE, M.A.E.; ABREU, C.M.P.; XISTO, A.L.R.P.; CARVALHO, V.D. Farinha de folhas de mandioca I efeito da secagem sobre a atividade da linamarase. Ciência Agrotécnica, v.26, n.2, p.368-374, 2002.

FARIAS, L.A.; LOPES, J.B.; FIGUEIRÊDO, A.V.; ALBUQUERQUE, D.M.N.; ARAUJO NETO, A.L.;

RAMOS.; L.S.N. Pseudofruto do cajueiro (Anacardium occidentale L.) para suínos em crescimento: metabolismo de nutrientes e desempenho. Ciência Animal Brasileira, v.9, n.1, p.100-109, 2008.
HUE, K.T.; VAN, D.T.T.; LEDIN, I.; SPORNDLY, E.; WREDLE, E. Effect of feeding fresh, wilted and sun-dried foliage from cassava (Manihot esculenta, Crantz) on the performance of lambs and their intake of hydrogen cyanide.

Livestock science, v.131, n.2, p.155-161, 2010.

KIEFER, C.; MOURA, M.S.; SILVA, E.A.; SANTOS, A.P.; SILVA, C.M.; LUZ, M.F.; NATES, C.L. Respostas de suínos em terminação mantidos em diferentes ambientes térmicos. Revista Brasileira de Saúde e Produção Animal [Online], v.11, n.2, p.496-504, 2010.

LEAL, P.M.; NÃ̃̃̂S, I.A. Ambiência animal. In: CORTEZ, L.A.B.; MAGALHÃES, P.S.G. (Org.). Introdução à engenharia agrícola. Campinas, SP: Unicamp, 1992. p.121135.

LY, N.T.H.; NGOAN, L.D.; VERSTEGEN, M.W.A.; HENDRIKS, W.H. Inclusion of ensiled cassava KM94 leaves in diets for growing pigs in vietnam reduces growth rate but increases profitability. Asian-Australasian Journal of Animal Science, v.24, n.8, p.1157-1163, 2011.

MATTERSON, L.D.; POTTER, L.M.; STUTUZ, N.W. et al. The metabolizable energy of feed ingredients for chickens. Research Reports, v.7, p.3-11, 1965.

MODESTI, C.F.; CORRÊA, A.D.; OLIVEIRA, E.D.; ABREU, C.M.P.; SANTOS, C.D. Caracterização de concentrado protéico de folhas de mandioca obtido por precipitação com calor e ácido. Ciência e Tecnologia de Alimentos, v.27, n.3, p.464-469, 2007. 
OLIVEIRA, M.C.; MARQUES, R.H.; GRAVENA, R.A.; TRALDI, A.B.; GODOY, C.R.; MORAES, V.M.B.

Fitase em dietas com níveis reduzidos de fósforo não-fítico para frangos de corte. Biotemas, v.22, n. 4, p. 169-176, 2009.

PARRA, A.R.P.; MOREIRA, I.;

FURLAN, A.C.; PAIANO, D.;

SCHERER, C.; CARVALHO, P.L.O.

Utilização da casca de café na alimentação de suínos nas fases de crescimento e terminação. Revista Brasileira de Zootecnia, v.37, n.3, p.433-442, 2008.

PARTANEN, K.; JALAVA, T.;

VALAJA, J. Effects of a dietary organic acid mixture ando $f$ dietary fibre levels on ileal and faecal nutriend apparent digestibility, bacterial nitrogen flow, microbial metabolite concentrations and rate of passage in the digestive tract of pigs. Animal, v.1, p.389-401, 2007.

PUPA, J.M.R. Óleos e gorduras na alimentação de aves e suínos.

Nutritime, v.1, n.1, p.69-73, 2004.

ROSTAGNO, H.S.; ALBINO, L.F.;DONZELE, J.L.; GOMES, P.C.; OLIVEIRA, R.F.; LOPES, D.C.; FERREIRA, A.S.; BARRETO, S.L.T.

Tabelas Brasileiras para aves $\mathrm{e}$ suínos: composição de alimentos e exigências nutricionais. Viçosa, MG: Universidade Federal de Viçosa, 2005. 186p.

SATH, K; BORIN, K; PRESTON, T.R. Effect of levels of sun-dried cassava foliage on growth performance of cattle fed reice straw. Livestock Research for rural development, v.20, n.7, p.1-12, 2008. Supl.
SELLE, P.H.; COWIENSON, A.J.; RAVINDRAN, V. Consequences of calcium interections with phytate and phytase for poultry and pigs. Livestock Science, v.124, n.1-3, p.126-141, 2009.

SOUZA, A.S.; ROCHA JÚNIOR, V.R.; MOTA, A.D.S.; PALMA, M.N.N.; FRANCO, M.O.; DUTRA, E.S.; SANTOS, C.C.R.; AGUIAR, A.C.R.; OLIVEIRA, C.R.; ROCHA, W.J.B. Valor nutricional de frações da parte aérea de quatro variedades de mandioca. Revista Brasileira de Saúde e Produção Animal [Online], v.12, n.2, p.441-455, 2011.

\section{SAS INSTITUTE. SAS System for linear models. Cary, 1986. 211p.}

TEO, C.R.P.A.; PRUDENCIO, S.H.; COELHO, S.R.M.; TEO, M.S.

Obtenção e caracterização físicoquímica de concentrado protéico de folhas de mandioca. Revista Brasileira de Engenharia Agrícola e Ambiental, v.14, n.9, p.993-999, 2010.

WHITE, H.M.; RICHERT, B.T.; SCHINCKEL, A.P.; BURGUESS, J.R.; DONKIN, S.S.; LATOUR, M.A. Effects of temperature stress on growth performance and bacon quality in growfinish pigs housed at two densities. Journal of Animal Science, v.86, p.1789-1798, 2008.

Data de recebimento: 11/10/2011

Data de aprovação: 18/06/2012 